Indonesian Journal of Electronics and Instrumentation Systems (IJEIS)

Vol.8, No.1, April 2018, pp. 25 36

ISSN (print): 2088-3714, ISSN (online): 2460-7681

DOI: $10.22146 /$ ijeis.30978

\title{
Sistem Pengukuran Modulus Elastisitas Beton Menggunakan Metode Ultrasonic Pulse Velocity
}

\author{
Amanda Purwanto*1, Abdul Ro'uf ${ }^{2}$ \\ ${ }^{1}$ Prodi Elektronika dan Instrumentasi, DIKE, FMIPA, UGM, Yogyakarta, Indonesia \\ ${ }^{2}$ Departemen Ilmu Komputer dan Elektronika, FMIPA, UGM, Yogyakarta, Indonesia \\ e-mail: *11 amanda.purwanto@mail.ugm.ac.id, ${ }^{2}$ rouf@mail.ugm.ac.id
}

\begin{abstract}
Abstrak
Saat ini, metode pengujian yang merusak umumnya dilakukan untuk mengetahui nilai modulus elastistisitas pada beton. Namun, hal tersebut dianggap kurang efektif karena diharuskan untuk menghancurkan tiap beton yang diuji. Pengujian dengan menggunakan metode Ultrasonic Pulse Velocity (UPV) dapat menjadi solusi dalam mendapatkan nilai modulus elastisitas beton tanpa harus merusaknya.

Cara kerja dari sistem UPV adalah dengan cara memancarkan gelombang ultrasonik pada beton. Nilai cepat rambat gelombang yang dibutuhkan untuk merambat pada suatu beton dapat digunakan dalam penghitungan nilai modulus elastisitas. Dalam sistem ini digunakan modul HC-SR04 sebagai pembangkit frekuensi sebesar $40 \mathrm{kHz}$, penguat gelombang yang diterima oleh receiver serta penghitung waktu. Tegangan yang dihasilkan oleh transmitter modul HC-SRO4 adalah 10 volt, sehingga harus dikuatkan dayanya dan tegangannya agar gelombang mampu menembus beton.

Hasil penelitian menunjukan bahwa nilai kesalahan pada pengukuran kecepatan gelombang melalui UPV dengan modul HC-SR04 jika dibandingkan dengan UPV Pundit memiliki nilai rata-rata 18,2\%. Modulus elastisitas dinamis yang dihasilkan dari pengukuran alat UPV dengan modul HC-SRO4 jika dibandingkan dengan modulus elastisitas statis melalui pengujian yang merusak memiliki nilai yang cenderung sebanding dan lebih tinggi dengan presentase diantara 45\% - 249\%. Nilai modulus elastisitas dari alat UPV Pundit yang dibandingkan dengan nilai modulus elastisitas statis menghasilkan presentase diantara $30 \%$ $388 \%$.
\end{abstract}

Kata kunci - Non-Destructive Testing, Ultrasonic Pulse Velocity, modul HC-SR04, modulus elastisitas beton

\begin{abstract}
Modulus of elasticity of concrete usually measured by Destructive Testing which is not considered as an effective way, because It will destroy the concrete. Ultrasonic Pulse Velocity can be a solution to measure value of modulus of elasticity without destructing it. The concept of the system is to look for velocity of wave, then put the value into modulus elasticity formula.

UPV system will transmit ultrasonic wave through concrete. HC-SRO4 used for generating $40 \mathrm{kHz}$ wave, increasing voltage of wave on receiver, and calculating time travel. The voltage of wave sent by $\mathrm{HC}$-SRO4 is only about 10 volt, so that power and voltage of wave has to be amplified. Piezoelectric is used as a transducer which can converts electrical to mechanical energy.

The results of this research shows that error value on wave velocity measurement have an average value for about 18,2\% compared to result of UPV Pundit. Dynamic modulus of elasticity that is obtained by UPV system with HC-SRO4 is compared to value of static modulus of elasticity from compressive test. Ratio between two values is about $45 \%-249 \%$. Then, ratio between dynamic modulus of elasticity attained by UPV Pundit and static modulus of elasticity is about $30 \%-388 \%$.
\end{abstract}

Keywords-Non-Destructive Testing, Ultrasonic Pulse Velocity, HC-SR04, modulus of elasticity of concrete

Received December $3^{\text {rd }}, 2017$; Revised March 23 ${ }^{\text {th }}, 2018$; Accepted April 29 $9^{\text {th }}, 2018$ 


\section{PENDAHULUAN}

Beton adalah suatu bahan bangunan yang digunakan dalam membangun sebuah konstruksi seperti rumah, bangunan tinggi, dan jembatan. Setiap beton memiliki sifat elastisitas yang merupakan kemampuan untuk berdeformasi sementara saat diberikan beban, tanpa perubahan yang permanen. Sifat elastisitas pada suatu beton dapat dianalisis menggunakan parameter modulus elastisitas yang didefinisikan sebagai kemiringan kurva tegangan dan regangan pada wilayah deformasi elastis yang dapat diketahui ketika diberikan suatu beban [1]. Namun, pengujian tersebut dapat merusak dan menghancurkan beton. Oleh karena pengujiannya yang bersifat merusak, maka dibutuhkan pengujian beton yang tidak mengakibatkan kerusakan pada beton.

Salah cara pengujian tidak merusak atau Non-Destructive Test yang dapat dilakukan untuk menguji nilai modulus elastisitas pada beton adalah menggunakan metode Ultrasonic Pulse Velocity [2]. Metode tersebut akan menghitung cepat rambat gelombang ultrasonik yang dibutuhkan untuk merambat pada suatu beton. Nilai cepat rambat gelombang ultrasonik dapat digunakan untuk menghitung nilai modulus elastisitas. Kecepatan gelombang ultrasonik yang merambat pada beton akan dipengaruhi oleh kekakuan elastisitas. Kecepatan gelombang UPV akan mengalami penurunan pada beton yang memiliki pemadatan kurang baik atau kerusakan pada butiran material [3]. Modulus elastisitas dinamis adalah nilai yang dihasilkan dari pengujian Non-Destructive Testing seperti Ultrasonic Pulse Velocity, sedangkan nilai modulus elastisitas dihasilkan dari pengujian Destructive Testing seperti Compression Test [4].

Selain itu, penelitian yang bertujuan untuk membuat sistem pendeteksi kecacatan pada suatu benda padat dengan gelombang ultrasonik yang menggunakan metode pantul juga dilakukan. Komponen yang digunakan adalah generator fungsi, rangkaian penguat, sensor ultrasonik, osiloskop, dan benda uji berbentuk silinder. Amplitudo gelombang yang diterima oleh receiver akan diamati melalui osiloskop untuk melihat adanya perubahan karena perbedaan medium benda. Salah satu hasil yang didapat adalah gelombang ultrasonik sebesar $40 \mathrm{kHz}$ dapat mendeteksi kecacatan benda padat serta setiap bentuk kecacatan pada benda padat mempunyai pola gelombang yang berbeda [5].

Penelitian tentang hubungan antara modulus elastisitas dinamis menggunakan metode Ultrasonic Pulse Velocity dengan umur beton. Terdapat lima sampel beton yang terdiri dari komposisi air-semen yang divariasikan. Pada tiap beton akan diuji nilai modulus elastisitas pada hari ke-7, 14, 28, 90, dan 120. Modulus elastisitas dinamis akan meningkat seiring waktu. Selain itu, modulus elastisitas akan mengalami penurunan seiring dengan meningkatnya rasio air-semen [6].

Hubungan antara nilai modulus elastisitas dinamis yang diuji melalui alat UPV dengan variasi bahan pada beton juga diteliti [7]. Beton uji divariasikan pada tiga jenis aggregat halus, yaitu seri A (pasir sungai), seri B (pasir bangunan), dan seri C (campuran antara pasir sungai serta pasir bangunan). Selain itu komposisi semen-air akan dicampurkan secara bervariasi dengan fly ash. Hasil percobaan menunjukan bahwa beton seri B yang menggunakan 100\% pasir bangunan memiliki elastisitas dinamis yang nilainya lebih rendah dari seri A yang menggunakan pasir sungai. Pada seri $\mathrm{C}$ yang memiliki campuran $50 \%$ pasir bangunan dan $50 \%$ pasir sungai menghasilkan nilai UPV, dan modulus elastisitas dinamis yang lebih tinggi, baik saat menggunakan semen ataupun menggunakan campuran fly ash. Pada campuran seri A, B, dan C yang kandungan semennya digantikan oleh fly ash menunjukan bahwa UPV, dan modulus elastisitas dinamis mengalami penurunan dengan kenaikan jumlah kandungan fly ash pada beton.

Berdasarkan latar belakang tersebut akan dilakukan penelitian yang bertujuan untuk mengukur nilai modulus elastisitas pada beton menggunakan metode ultrasonic pulse velocity. Kemudian, nilai modulus elastisitas dinamis akan dibandingkan dengan modulus elastisitas statis untuk melihat korelasi antara dua nilai tersebut.

IJEIS Vol. 8, No. 1, April 2018: 25 - 36 


\section{METODE PENELITIAN}

Sistem yang dirancang dalam penelitian ini adalah sebuah alat yang berfungsi untuk mengetahui nilai modulus elastisitas tanpa harus merusak beton. Alat ini menerapkan metode Ultrasonic Pulse Velocity yang akan mencari nilai dari cepat rambat gelombang yang dibutuhkan untuk memancarkan gelombang ultrasonik yang memiliki frekuensi $40 \mathrm{kHz}$ dari transmitter menuju receiver. Probe transmitter dan receiver yang digunakan dalam sistem ini adalah sensor piezoelektrik.

Cepat rambat gelombang dapat diketahui dari variabel jarak tempuh gelombang yang dibagi dengan waktu tempuh cepat rambat gelombang. Waktu tempuh gelombang adalah waktu yang diperlukan gelombang untuk menembus material dari saat pertama gelombang dipancarkan oleh transmitter hingga diterima oleh receiver. Cepat rambat gelombang pada suatu medium bergantung pada sifat elastisitas dan massa jenisnya, sehingga dapat digunakan untuk menentukan sifat beton. Jika massa jenis dan rasio poisson sudah diketahui, maka modulus elastisitas dinamis dapat ditemukan.

Cara kerja dari alat ini menggunakan konsep dari HC-SR04 yang merambatkan gelombang ultrasonik melalui udara dalam mendeteksi jarak suatu benda. Namun, tegangan yang dibutuhkan agar gelombang ultrasonik mampu merambat melalui beton adalah yang lebih besar dari 60 Volt, sedangkan HC-SR04 hanya menghasilkan tegangan sebesar 10 Volt. Oleh karena itu, gelombang keluaran dari modul HC-SR04 akan dikuatkan terlebih dahulu sebelum diteruskan ke transmitter. Selain itu, transduser asli dari HC-SR04 akan diganti dengan sensor piezzo yang dapat merambatkan gelombang ultrasonik melalui suatu material.

Keluaran dari modul HC-SR04 akan dikuatkan dayanya terlebih dahulu menggunakan LM386. Namun tegangan keluaran dari LM386 hanya akan berubah menjadi 11 volt, karena LM386 mendapatkan tegangan referensi dari power supply sebesar 11 volt. Setelah itu, gelombang tersebut akan diteruskan menuju transformator step up untuk dikuatkan tegangannya menjadi 95 Volt [8]. Pulsa yang sudah dikuatkan selanjutnya akan diteruskan menuju piezzo yang akan memancarkan gelombang ultrasonik ke beton. Waktu tempuh gelombang akan dihitung oleh mikrokontroler saat gelombang pertama kali dipancarkan oleh transmitter dan berhenti saat gelombang diterima oleh receiver. Metode yang digunakan dalam penelitian ini adalah direct yang berarti meletakan transmitter dan receiver berhadapan diantara beton. Gelombang yang telah diterima receiver memiliki tegangan dibawah 1 Volt, tetapi terdapat rangkaian penguat di dalam modul HC-SR04. Kemudian, waktu dan jarak yang ditempuh oleh beton digunakan untuk mencari cepat rambat gelombang yang merambat melalui beton. Nilai cepat rambat gelombang tersebut akan digunakan untuk mencari nilai modulus elastisitas. Untuk mempermudah tahapan perancangan alat dan memastikan proses kerja alat berjalan secara optimal, maka dibuatlah blok diagram penelitian yang ditunjukkan pada Gambar 1.

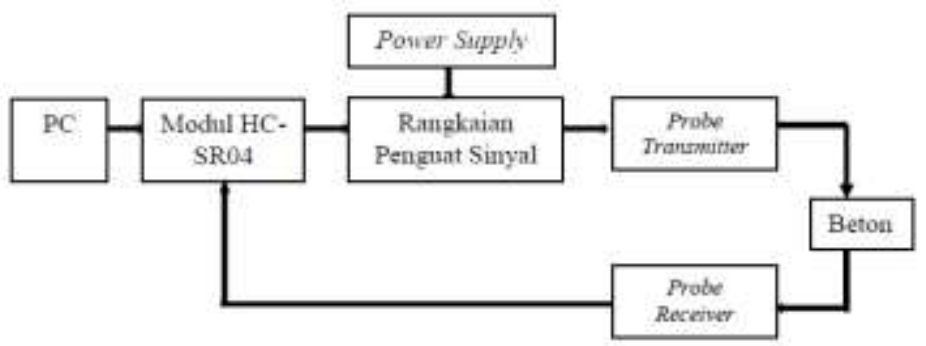

Gambar 1 Blok Diagram Penelitian 


\section{1 Rancangan Perangkat Keras}

Perangkat keras yang digunakan dalam rangkaian ini adalah transmitter dan receiver. Transmitter terdiri dari Modul HC-SR04, LM386, transformator step up, dan sensor piezzo. Sedangkan sensor piezoelektrik yang berperan sebagai receiver akan dihubungkan langsung ke modul HC-SR04. Rancangan transmitter dan receiver ditunjukkan pada Gambar 2.

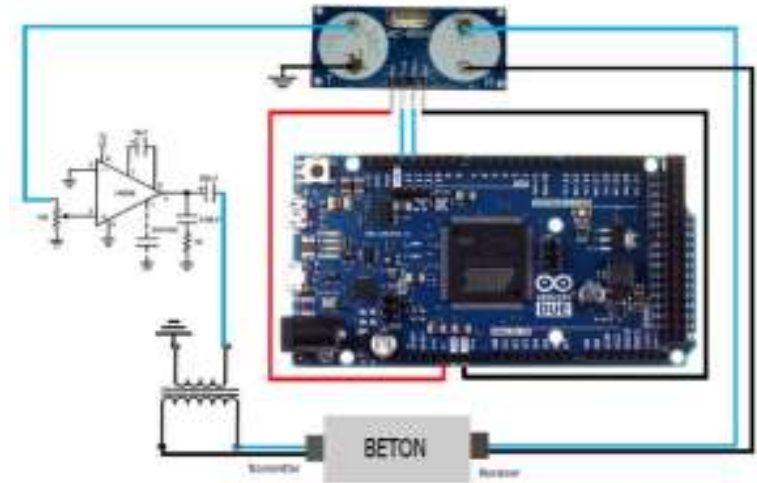

Gambar 2 Rancangan transmitter dan Receiver

\subsubsection{Rancangan Transmitter}

Rancangan hardware ini terdiri atas bagian mekanis dan elektronis sistem robot swarm yang dibuat. Bagian elektronis sistem ditunjukkan seperti dalam Gambar 1. Setiap robot akan memiliki spesifikasi hardware yang sama. Sebagai pusat pemroses data digunakan dua buah mikrokontroler AVR 8 bit yaitu tipe ATmega32 yang berperan sebagai master dan ATmega8 berperan sebagai slave. Keduanya akan bekerja sama secara paralel.

\subsubsection{Rancangan Receiver}

Setelah sinyal dipancarkan oleh transmitter, gelombang tersebut akan ditangkap oleh receiver. Gelombang akan lebih mudah terbaca di osiloskop jika dikuatkan kembali. Komponen yang digunakan untuk memperkuat daya gelombang pada rangkaian penguat receiver adalah IC CA3140, sehingga sinyal yang diterima dapat diterima oleh Arduino Due. Gelombang yang ditangkap oleh receiver dapat memberikan informasi mengenai waktu yang ditempuh dari transmitter menuju receiver.

\subsection{Rancangan Objek Uji}

Terdapat dua jenis penelitian yang akan dilakukan yaitu, pengujian hubungan antara tebal dengan waktu tempuh beton dan pengujian cepat rambat gelombang ultrasonik untuk mencari nilai modulus elastisitas dinamis. Pada pengujian hubungan antara tebal dengan waktu tempuh beton terdapat 3 objek uji yang memiliki komposisi bahan yang sama, tetapi memiliki ketinggian yang berbeda yaitu 2,5 cm; 4,2 cm; dan 7,4 cm. Gambar 3 menunjukan rancangan beton untuk pengujian hubungan antara tebal dan waktu tempuh beton.

Kemudian, untuk melakukan pengujian cepat rambat gelombang digunakan lima objek uji beton silinder yang memiliki diameter $=7,5 \mathrm{~cm} / 8 \mathrm{~cm}$ dan tinggi $=15 \mathrm{~cm} / 16 \mathrm{~cm}$. Gambar 4 menunjukan rancangan beton untuk pengujian modulus elastisitas. Lima beton tersebut terdiri dari beton dengan kualitas sangat bagus, bagus, diragukan, jelek dan sangat jelek. 


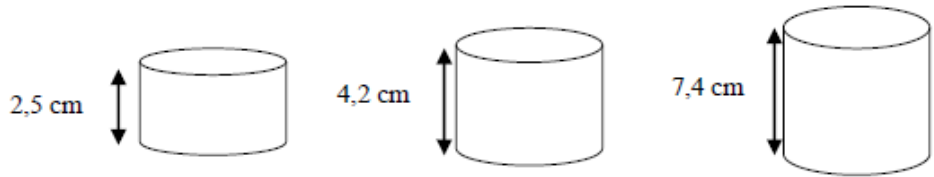

Gambar 3 Benda uji dengan ketebalan yang berbeda

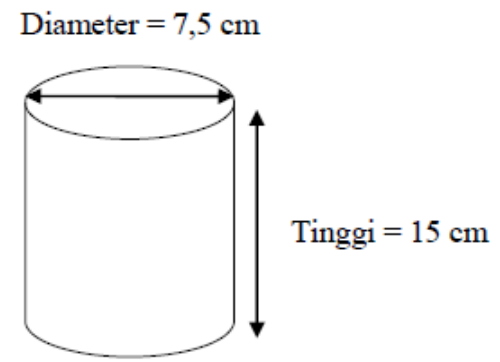

Gambar 4 Benda uji dengan tinggi $15 \mathrm{~cm}$

\subsection{Rancangan Perangkat Lunak (Software)}

Program yang digunakan dalam penelitian ini menggunakan bahasa pemograman $\mathrm{C}++$ yang menggunakan Arduino IDE (Integrated Development Environment). Diagram alir dibuat terlebih dahulu sebelum membuat program, agar memudahkan dalam merancang program. Diagram alir disesuaikan dengan cara kerja dari modul HC-SR04. Setelah mikrokontroler dihubungkan ke PC, tegangan positif akan diberikan pada pin Trigger selama $10 \mathrm{uS}$. Kemudian, sensor akan mengirimkan 8 step sinyal ultrasonik dengan frekuensi 40kHz. Selanjutnya, sinyal akan diterima oleh pin Echo. Waktu tempuh adalah selisih saat sinyal dikirimkan hingga diterima.

\section{HASIL DAN PEMBAHASAN}

Bab ini berisi hasil dari pembahasan dan pengujian yang telah dilakukan untuk mengukur modulus elastisitas dengan metode ultrasonic pulse velocity dan menganalisis korelasi antara modulus elastisitas dinamis dan statis. Pengujian dilakukan pada transmitter, receiver, dan cepat rambat gelombang pada objek uji. Pengujian transmitter dan receiver digunakan untuk mengetahui besarnya gelombang yang digunakan untuk memancarkan dan menerima gelombang,. Pengujian cepat rambat gelombang digunakan untuk menemukan nilai modulus elastisitas statis pada beton, kemudian nilai dari modulus elastisitas statis akan dianalisis hubungannya dengan modulus elastisitas dinamis.

\subsection{Pengujian Hubungan Antara Waktu Tempuh dengan Tebal Beton}

Pengujian dilakukan kepada tiga buah beton dengan komposisi material yang sama, tetapi memiliki tebal yang berbeda. Tujuan dari pengujian ini adalah untuk mencari hubungan antara cepat rambat gelombang dengan ketebalan beton. Tiga buah beton yang diuji memiliki tinggi $2,5 \mathrm{~cm} ; 4,2 \mathrm{~cm}$; dan $7,4 \mathrm{~cm}$. Tiap beton diambil data waktu tempuhnya sebanyak $200 \mathrm{kali}$, kemudian diambil nilai rata-rata waktu tempuh pada tiap beton. Gambar 5 menunjukan grafik hubungan antara rata-rata waktu tempuh yang dibutuhkan untuk merambat dengan tebal masing-masing beton. Grafik tersebut menunjukan bahwa semakin tebal beton, maka akan semakin lama waktu tempuh yang dibutuhkan untuk merambat pada beton. 


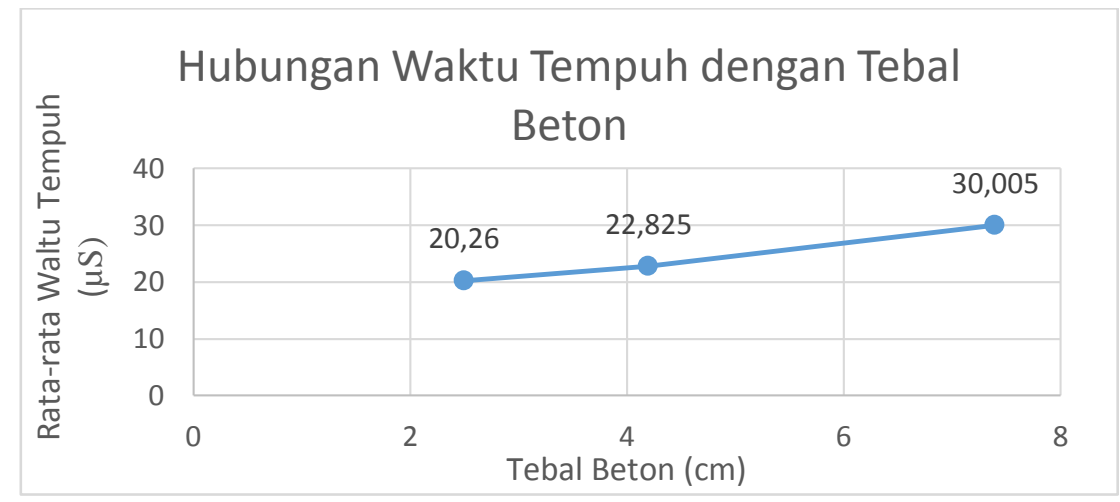

Gambar 5 Grafik hubungan antara rata-rata waktu tempuh dengan tebal beton.

\subsection{Pengujian Waktu Tempuh Gelombang Pada Beton}

Terdapat lima benda uji yang akan diuji nilai cepat rambat gelombangnya dalam menggunakan alat UPV berbasis modul HC-SR04. Benda uji berbentuk silinder dengan tinggi $15 \mathrm{~cm} / 16 \mathrm{~cm}$ dan diameter 7,5 cm / $8 \mathrm{~cm}$. Kemudian, nilai dari hasil pengukuran tersebut akan dibandingkan dengan hasil pengukuran menggunakan UPV Pundit. Kalibrasi dilakukan pada alat UPV Pundit menggunakan kalibrator besi yang mempunyai nilai waktu tempuh $25,7 \mu \mathrm{S}$. Jika alat UPV Pundit saat menguji kalibrator besi belum menunjukan nilai tersebut, maka tombol set referensi diatur agar nilai yang dihasilkan menjadi $25,7 \mu \mathrm{S}$.

\subsubsection{Pengujian Beton 1}

Gambar 6 menunjukan grafik hasil pengukuran waktu tempuh pada beton 1 menggunakan alat UPV berbasis modul HC-SR04 dengan rata-rata 25,445 $\mu$ S. Data yang diambil sebanyak 200 kali. Hasil pengukuran waktu tempuh UPV Pundit juga dilakukan sebagai nilai referensi. Nilai waktu tempuh yang dikeluarkan oleh UPV Pundit pada beton 1 adalah $29,7 \mu \mathrm{S}$.

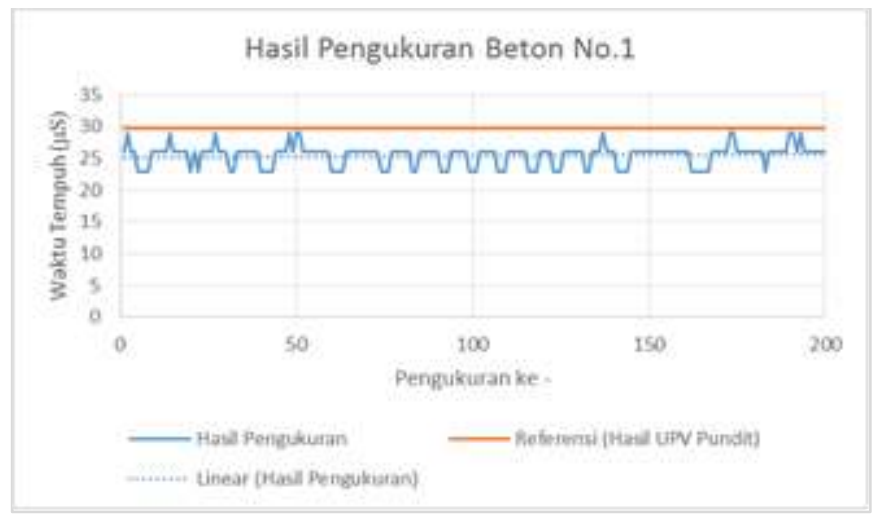

Gambar 6 Hasil pengukuran beton no. 1

\subsubsection{Pengujian Beton 2}

Gambar 7 menunjukan grafik hasil pengukuran waktu tempuh pada beton 3 menggunakan alat UPV berbasis modul HC-SR04 dengan rata-rata 31,745 $\mu$ S. Data yang diambil sebanyak 200 kali. Hasil pengukuran waktu tempuh UPV Pundit juga dilakukan sebagai nilai referensi. Nilai waktu tempuh yang dikeluarkan oleh UPV Pundit pada beton 2 adalah 37,1 $\mu \mathrm{S}$. 


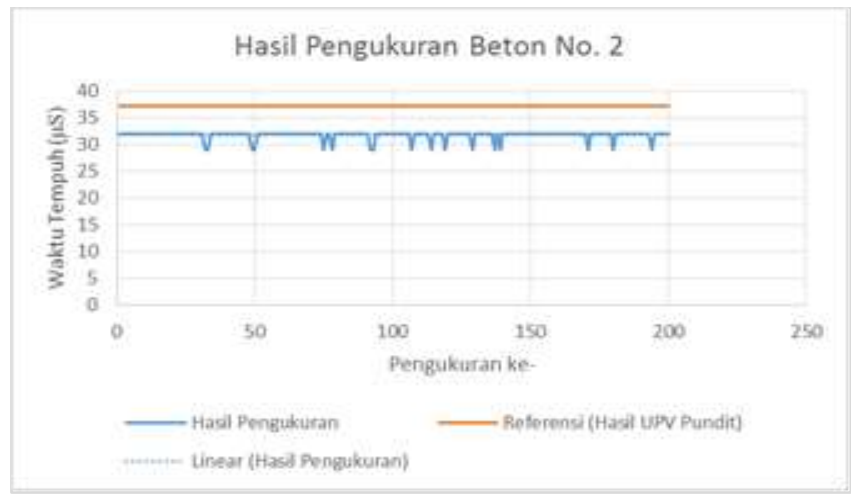

Gambar 7 Hasil pengukuran beton no. 2

\subsubsection{Pengujian Beton 3}

Gambar 8 menunjukan grafik hasil pengukuran waktu tempuh pada beton 4 menggunakan alat UPV berbasis modul HC-SR04 dengan rata-rata 59,03 $\mu$ S. Data yang diambil sebanyak 200 kali. Hasil pengukuran waktu tempuh UPV Pundit juga dilakukan sebagai nilai referensi. Nilai waktu tempuh yang dikeluarkan oleh UPV Pundit pada beton 3 adalah 48,2 $\mu$ S .

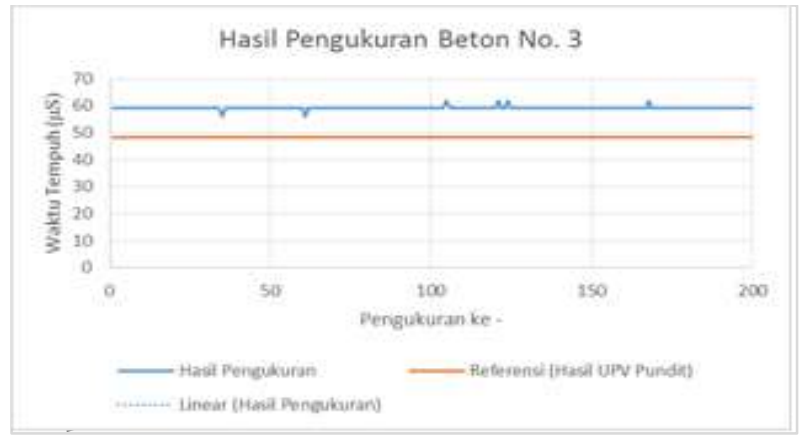

Gambar 8 Hasil pengukuran beton no. 3

\subsubsection{Pengujian Beton 4}

Gambar 9 menunjukan grafik hasil pengukuran waktu tempuh pada beton 4 menggunakan alat UPV berbasis modul HC-SR04 dengan rata-rata 68,472 $\mu \mathrm{S}$. Data yang diambil sebanyak 200 kali. Hasil pengukuran waktu tempuh UPV Pundit juga dilakukan sebagai nilai referensi. Nilai waktu tempuh yang dikeluarkan oleh UPV Pundit pada beton 4 adalah 86,7 $\mu \mathrm{S}$.

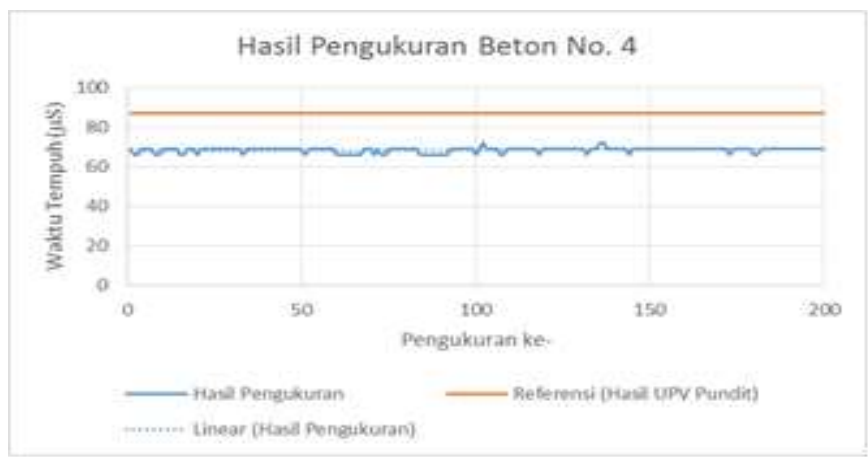

Gambar 9 Hasil pengukuran beton no. 4 


\subsubsection{Pengujian Beton 5}

Gambar 10 menunjukan grafik hasil pengukuran waktu tempuh pada beton 5 menggunakan alat UPV-modul HC-SR04 dengan rata-rata 84,155 $\mu$ S. Data yang diambil sebanyak 200 kali. Hasil pengukuran waktu tempuh UPV Pundit juga dilakukan sebagai nilai referensi. Nilai waktu tempuh yang dikeluarkan oleh UPV Pundit pada beton 4 adalah $105 \mu \mathrm{S}$.

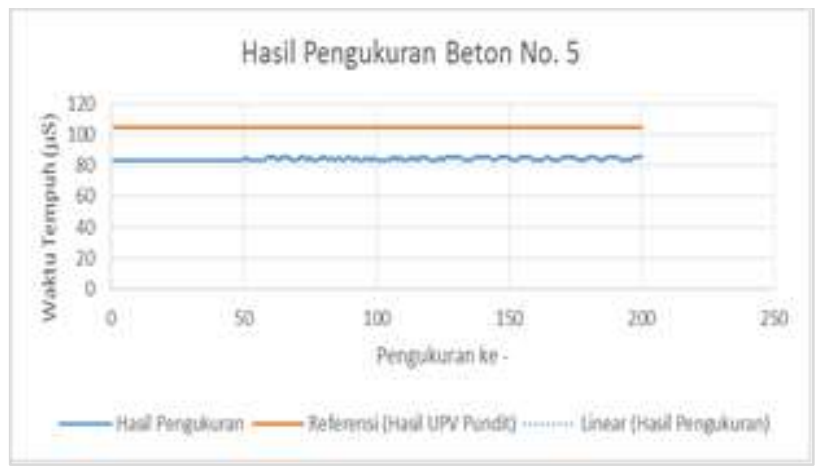

Gambar 10 Hasil pengukuran beton no. 5

\subsubsection{Analisis Data Cepat Rambat Gelombang}

Analisis yang dilakukan adalah bagaimana hubungan nilai waktu tempuh yang dihasilkan oleh alat UPV Pundit dengan alat UPV yang mengggunakan modul HC-SR04. Setelah nilai modulus elastisitas dinamis ditemukan, hubungan antara modulus elastisitas dinamis dengan modulus elastisitas statis dianalisis. Nilai error pada hasil pengukuran dapat diketahui menggunakan persamaan (1).

$$
\text { Error }=\left|\frac{t_{1}-t_{2}}{t_{2}} \times 100 \%\right|
$$

Nilai $t_{1}$ adalah nilai waktu tempuh alat UPVdengan Modul HC-SR04 $(\mu \mathrm{S})$, sedangkan nilai $t_{2}=$ adalah nilai waktu tempuh alat UPV Pundit $(\mu S)$. Kemudian, hasil dari pengukuran nilai error ditunjukan pada Tabel 1. Hubungan antara Error dan UPV Pundit digambarkan pada Gambar 11.

Tabel 1 Nilai error cepat rambat gelombang

\begin{tabular}{|c|c|c|c|}
\hline No & $\begin{array}{c}\text { UPV menggunakan } \\
\text { modul HC-SR04 }\end{array}$ & UPV Pundit & $\begin{array}{c}\text { Nilai Error } \\
(\%)\end{array}$ \\
\hline 1 & 25,445 & 29,7 & 14 \\
\hline 2 & 58,985 & 37,1 & 14 \\
\hline 3 & 59,03 & 48,2 & 22 \\
\hline 4 & 68,47236 & 86,7 & 21 \\
\hline 5 & 84,155 & 105 & 20 \\
\hline \multicolumn{4}{|c|}{ Error Rata- Rata } \\
\hline
\end{tabular}




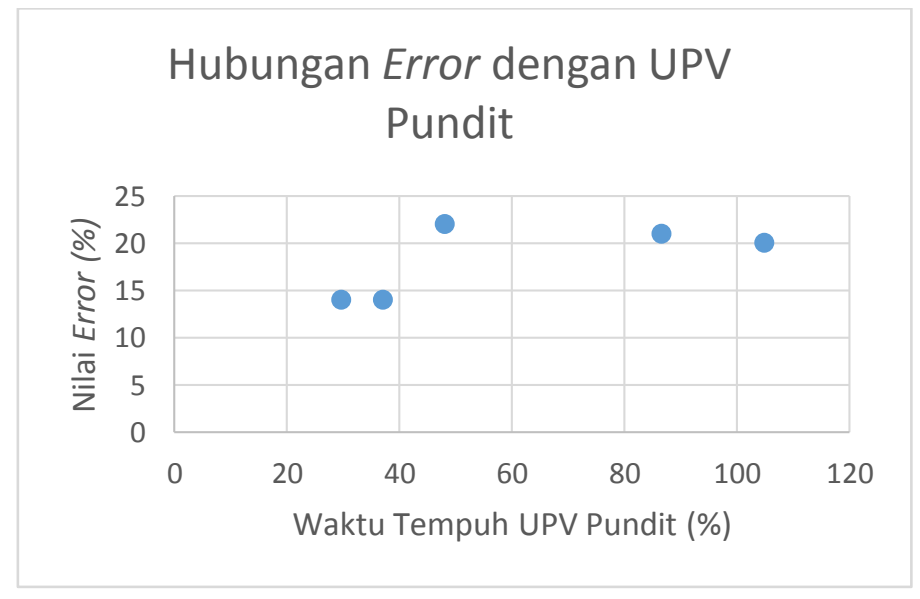

\subsection{Nilai Modulus Elastisitas Dinamis (Ed)}

Setelah waktu tempuh gelombang ditemukan, nilai modulus elastisitas dinamis dapat dihitung melalui persamaan (2) yang menghubungkan antara cepat rambat gelombang dan modulus elastisitas dinamis. Terdapat tiga variabel yang harus dicari terlebih dahulu yaitu cepat rambat gelombang, poisson ratio dan massa jenis.

$$
E_{d}=V^{2} \rho \frac{(1+\mu)(1-2 \mu)}{(1-\mu)}
$$

$E_{d}(\mathrm{MPa})$ adalah nilai modulus elastisitas dinamis, $\rho\left(\mathrm{kg} / \mathrm{m}^{3}\right)$ adalah massa jenis yang didapat dari perbandingan antara massa dengan volume beton, $V(\mathrm{~km} / \mathrm{s})$ adalah nilai ultrasonic pulse velocity yang didapatkan dari perbandingan antara nilai waktu tempuh dengan tebal beton, dan $\mu$ adalah nilai poisson ratio. Dalam mencari poisson ratio dapat ditemukan dengan mengasumsikan berdasarkan nilai kuat tekannya masing-masing. Beton dengan nilai kuat tekan berada di bawah 19,5 MPa memiliki nilai poisson ration 0,26 . Beton yang memiliki nilai kuat tekan diantara 19,5 MPa dan 76,5 MPa memiliki nilai rasio poisson sebesar 0,23. Pada beton yang memiliki nilai kuat tekan di atas 76,5 MPa memiliki nilai rasio poisson sebesar 0,18 [9]. Untuk mendapatkan nilai kuat tekan pada tiap beton digunakan fungsi yang ditunjukan pada persamaan (3) yang didapatkan dari hasil korelasi antara kuat tekan dan cepat rambat gelombang [10]. Dari hasil perhitungan tersebut didapatkan nilai rasio poisson.

$$
S_{n}=0.3161 e^{1.03 V_{n}}
$$

$\mathrm{V}_{\mathrm{n}}(\mathrm{km} / \mathrm{s})$ adalah nilai cepat rambat gelombang yang diuji menggunakan alat UPV, sedangkan $\mathrm{S}_{\mathrm{n}}(\mathrm{MPa})$ adalah nilai kuat tekan beton. Setelah nilai cepat rambat gelombang, massa jenis, dan rasio poisson ditemukan, maka nilai modulus elastisitas dinamis dapat dihitung. Tabel 2 menunjukan nilai modulus elastisitas dinamis pada tiap beton.

Tabel 2 Nilai modulus elastisitas dinamis

\begin{tabular}{|c|c|}
\hline No. Beton & Modulus Elastisitas Dinamis (Mpa) \\
\hline Beton 1 & 8254,76 \\
\hline Beton 2 & 5431,55 \\
\hline Beton 3 & 1244,14 \\
\hline Beton 5 & 470,32 \\
\hline
\end{tabular}




\subsection{Nilai Modulus Elastisitas Statis (Es)}

Beton diuji menggunakan compression test "Riehle" yang berkapasitas mesin 60.000 lbs untuk mengatahui nilai modulus elastisitas statis. Pengujian dilaksanakan di di Laboratorium Bahan Bangunan, Teknik Sipil, Universitas Gadjah Mada. Prinsip kerja dari pengujian ini adalah membandingkan antara tegangan dengan regangan pada beton jika diberikan suatu beban. Gambar proses pengujian modulus elastisitas statis ditunjukan pada Gambar 12. Nilai modulus elastisitas statis ditunjukan pada Tabel 3.

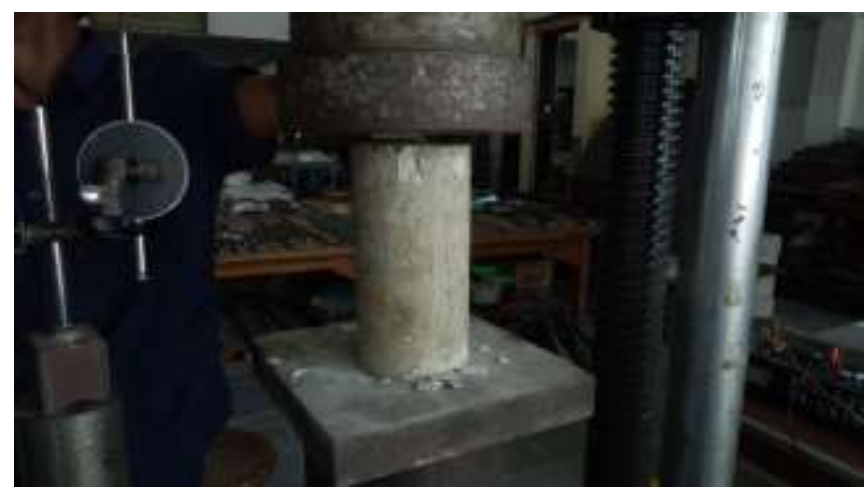

Gambar 12 Compression Test

Tabel 3. Nilai modulus elastisitas statis

\begin{tabular}{|c|c|}
\hline No. Beton & $\begin{array}{c}\text { Modulus Elastisitas Statis } \\
(\mathrm{MPa})\end{array}$ \\
\hline Beton 1 & 4408,10 \\
\hline Beton 2 & 3625,17 \\
\hline Beton 3 & 554,16 \\
\hline Beton 5 & 1172,25 \\
\hline
\end{tabular}

\subsection{Korelasi Modulus Elastisitas Dinamis dan Modulus Elastisitas Statis}

Kedua nilai modulus elastisitas dinamis yang dihasilkan melalui UPV dengan modul HC-SR04 dan UPV Pundit dibandingkan dengan nilai modulus elastisitas statis. Tabel 4 adalah perbandingan antara modulus elastisitas dinamis dan modulus elastisitas statis.

Tabel 4 Perbandingan antara modulus elastisitas dinamis dan modulus elastisitas statis.

\begin{tabular}{|c|c|c|c|c|c|}
\hline \multirow{2}{*}{$\begin{array}{l}\text { No. } \\
\text { Beton }\end{array}$} & \multicolumn{2}{|c|}{ Modulus Elastisitas Dinamis } & \multirow{2}{*}{$\begin{array}{c}\text { Modulus } \\
\text { Elastisitas } \\
\text { Statis } \\
\text { (Mpa) }\end{array}$} & \multirow{2}{*}{$\begin{array}{c}\text { Perbandingan } \\
\text { Modulus } \\
\text { Elastisitas } \\
\text { Statis dan } \\
\text { Dinamis (UPV } \\
\text { Pundit) }\end{array}$} & \multirow{2}{*}{$\begin{array}{l}\text { Perbandingan } \\
\text { Modulus } \\
\text { Elastisitas Statis } \\
\text { dan dinamis } \\
\text { (UPV HC-SRO4) }\end{array}$} \\
\hline & $\begin{array}{l}\text { UPV Pundit } \\
\text { (Mpa) }\end{array}$ & $\begin{array}{l}\text { UPV dengan } \\
\text { HC-SRO4 } \\
\text { (Mpa) }\end{array}$ & & & \\
\hline $\begin{array}{c}\text { Beton } \\
1\end{array}$ & 6058,9 & 8254,76 & 4408,10 & $73 \%$ & $53 \%$ \\
\hline $\begin{array}{c}\text { Beton } \\
2\end{array}$ & 3976,7 & 5431,55 & 3625,17 & $91 \%$ & $67 \%$ \\
\hline $\begin{array}{c}\text { Beton } \\
3\end{array}$ & 1866,0 & 1244,14 & 554,16 & $30 \%$ & $45 \%$ \\
\hline $\begin{array}{l}\text { Beton } \\
5\end{array}$ & 302,1 & 470,32 & 1172,25 & $388 \%$ & $249 \%$ \\
\hline
\end{tabular}




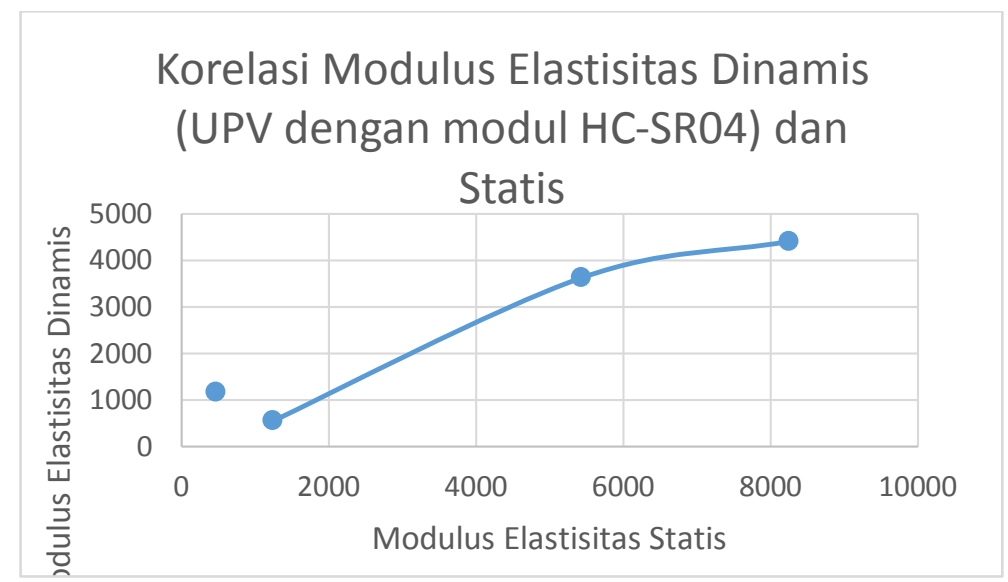

Gambar 13 Korelasi Modulus Elastisitas Dinamis (UPV modul HC-SR04) dan Statis

Hasil pengujian modulus elastisitas dinamis dari UPV Pundit dan statis menunjukan bahwa pengukuran antara modulus elastisitas dinamis dari UPV Pundit menghasilkan nilai yang sebanding, tetapi cenderung memiliki nilai yang lebih tinggi daripada nilai modulus elastisitas statis. Presentase perbandingan berada diantara 30\% - 388\%.. Perbandingan pengukuran antara modulus elastisitas dinamis dari UPV dengan modul HC-SR04 memiliki hasil yang sebanding, tetapi cenderung memiliki nilai yang lebih tinggi daripada nilai modulus elastisitas statis. Presentase perbandingan berada diantara 45\% - 249\%. Gambar 13 menunjukan korelasi antara nilai modulus elastisitas dinamis yang dihasilkan oleh UPV modul HC-SR04 dengan modulus elastisitas statis

\section{KESIMPULAN}

Dari hasil penelitian yang telah dilakukan dapat diambil kesimpulan sebagai berikut bahwa telah berhasil merancang sistem UPV pengukuran nilai cepat rambat gelombang pada beton yang dapat digunakan untuk menghitung nilai modulus elastisitas dinamis dengan menggunakan modul HC-SR04, selain itu error nilai cepat rambat gelombang yang dihasilkan oleh alat UPV dengan modul HC-SR04 jika dibandingkan dengan UPV Pundit memiliki nilai rata-rata 18,2 \% dan nilai modulus elastisitas dinamis yang dihasilkan oleh alat UPV dengan modul HC-SR04 jika dibandingkan dengan nilai modulus elastisitas statis memiliki nilai yang cenderung sebanding dan lebih tinggi dengan presentase diantara $45 \%-249 \%$.

\section{SARAN}

Untuk penelitian selanjutnya yang akan menggunakan metode Ultrasonic Pulse Velocity pada beton disarankan untuk mengembangkan sistem dengan prinsip yang diadaptasi dari cara kerja HC-SR04, tetapi dengan rangkaian pembangkit sinyal yang dapat menghasilkan gelombang ultrasonik dengan frekuensi lebih tinggi dari $40 \mathrm{kHz}$ dan menggunakan transduser ultrasonik yang dirancang khusus untuk beton. Selain itu, disarankan untuk menggunakan benda uji dengan variasi kualitas beton yang lebih banyak agar dapat memperkuat analisis. 


\section{DAFTAR PUSTAKA}

[1] H. Shao, J. Zhang, T. Fan, and Z. Li, "Electrical method to evaluate elastic modulus of early age concrete," Constr. Build. Mater., vol. 101, pp. 661-666, 2015.

[2] A. K. Chandrappa and K. P. Biligiri, "Influence of mix parameters on pore properties and modulus of pervious concrete: an application of ultrasonic pulse velocity," Mater. Struct., vol. 49, no. 12, pp. 5255-5271, 2016.

[3] H. S. Anggraeni, E. E. Susilo, and S. Wedhanto, "Perbandingan Kekuatan Beton Berdasarkan Hasil Ultrasonik Tes UPV," in Konferensi Nasional Teknik Sipil, 2013, vol. 7, no. KoNTekS 7, pp. 24-26.

[4] X. Lu, Q. Sun, W. Feng, and J. Tian, "Evaluation of dynamic modulus of elasticity of concrete using impact-echo method," Constr. Build. Mater., vol. 47, pp. 231-239, 2013.

[5] T. Nur Syahril Sidiq, A. Rouf, and T. Wahyu Supardi, "Sistem Deteksi Bentuk Kecacatan Benda Padat Menggunakan Teknik Variasi Sudut Ultrasonik," IJEIS (Indonesian J. Electron. Instrum. Syst., vol. 6, no. 1, p. 69, 2016.

[6] J. Malek and M. Kaouther, "Destructive and non-destructive testing of concrete structures Experimental study Materials characte ristics," Jordan J. Civ. Eng., vol. 8, no. 4, pp. 432-441, 2014.

[7] S. K. Rao, P. Sravana, and T. C. Rao, "Experimental studies in Ultrasonic Pulse Velocity of roller compacted concrete pavement containing fly ash and M-sand Studies in Ultrasonic Pulse Velocity of Roller compacted concrete pavement," Int. J. Pavement Res. Technol., vol. 9, no. 4, pp. 289-301, 2016.

[8] S. Swasoko and A. Rouf, "Rancang Bangun Pembangkit Pulsa Tiga Sensor Ultrasonik Untuk Pendeteksi Kecacatan Beton Berbasis Mikrokontroler," vol. 7, no. 2, pp. 197-208, 2017.

[9] H. Yildirim and O. Sengul, "Modulus of elasticity of substandard and normal concretes," Constr. Build. Mater., vol. 25, no. 4, pp. 1645-1652, 2011.

[10] P. Turgut, "Research into the correlation between concrete strength and UPV values," Civ. Eng., vol. 12, no. 12, pp. 1-7, 2010. 